\title{
Analysis on EMF characteristics for torque ripple reduction in BLAC motor intended for HVLS fan application
}

\author{
Nurfaezah Abdullah", Raja Nor Firdaus Raja Othman², Kasrul Abdul Karim ${ }^{3}$, Lim Seng Tat ${ }^{4}$ \\ 1,2,3 Fakulti Kejuruteraan Elektrik, Universiti Teknikal Malaysia Melaka, 76100 Durian Tunggal, Melaka, Malaysia \\ 1,2,3 Electrical Machine Design Research Laboratory, Centre of Robotics \& Automation, UTeM, 76100 Melaka, Malaysia \\ ${ }^{4}$ Altair Engineering SdnBhd, B3-10-7 Plaza Sentral, 5, JalanStesenSentral, 50470 Kuala Lumpur, Malaysia.
}

\begin{tabular}{l} 
Article Info \\
\hline Article history: \\
Received Jan 17, 2019 \\
Revised Jul 22, 2019 \\
Accepted Aug 3, 2019 \\
\hline
\end{tabular}

\section{Keywords:}

Brushless AC

EMF harmonics

FLUX 2D

FFT analysis

Torque ripples

\begin{abstract}
This paper analyzes the harmonic characteristics of electromagnetic force (EMF) in Brushless Alternating Current (BLAC) motor for High Volume Low Speed (HVLS) fan application. Vibration and noise are one of the main crucial things in HVLS fan application. It comes from torque ripples which can be detected by harmonics of Electro Magnetic Force (EMF). Commonly, there are a few methods to eliminate the noise and vibrations issue, but most literatures only focus on small motor and not intended for HVLS fan application. Thus, the objective of this paper is to eliminate the harmonics content in EMF at early stage design. Through EMF harmonics the expected torque produced could be used to select proper slot-pole number in order to eliminate the noise and vibrations issue. In here, the analysis involves three different slot-pole numbers which are 18s/20p, 12s/10p and 9s/8p BLAC model, respectively. All models have similar volume of permanent magnet. The analysis is carried out using FLUX 2D Finite Element Analysis (FEA) for EMF computational and transient torque computation. Later, Fast Fourier Transform (FFT) analysis is used to calculate the harmonics of EMF. The analysis stage includes the EMF parameter analysis, harmonics and torque ripples analysis. It was found that $18 \mathrm{~s} / 20 \mathrm{p}$ has higher output torque with the lowest $5 \%$ torque ripple value. As a conclusion, this paper presents low torque ripple in point of view of the EMF characteristics in designing HVLS fan.
\end{abstract}

This is an open access article under the CC BY-SA license.

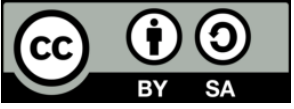

\section{Corresponding Author:}

Raja Nor Firdaus Raja Othman

Faculty of Electrical Engineering,

UniversitiTeknikal Malaysia, Melaka, Malaysia Hang Tuah Jaya,

76100 Durian Tunggal, Melaka, Malaysia.

Email: norfirdaus@utem.edu.my

\section{INTRODUCTION}

Brushless motor gains more attentions as the electric motor to drive a numerous application. The advantages of brushless motor such as light weight, longer lifetime, steady operation high efficiency and higher torque offered an extra credit to this type of motor. Above features mentioned are suitable for High Volume Low Speed Fan (HVLS) application. The systems required a powerful, high torque and High efficient motor to drive the blades at low speed range. The operation of the motor to run the HVLS fan is depending on the smoothest torque is produced. When the ripples occur the motor, stability is interrupted thus affect the existence of noise and vibrations [1-4]. Commonly, this issue is related to the torque ripple due to the interactions between stator and rotor. The electromagnetic force (EMF) harmonics that related to the 
torque ripple need to diminish as solution of this issue. Higher vibrations and noise will reduce the overall fan performances [5-7].

In Brushless motor, a torque ripple is one of the main problems that affect the motor performances. Inappropriate motor design which is lead to the harmonics in magneto motive force (MMF) is a factor that could increase the torque ripples [8-10]. There are many methods in literature that affect the torque ripples such as incompatible size of the tooth shape, inappropriate angle of permanent magnet and improper combinations of the slot-pole number of the motor [11-13]. Nevertheless, slot-pole number selection is continuously become the main parameter to be explored. The appropriate selection of the slot-pole will improve performance of the Brushless motor. The analysis on slot-pole number are widely covered for torque ripple minimization, space harmonics and concentrated windings for other type machine such permanent magnet synchronous motor (PMSM). Sun and Hong in their paper, investigated the effect of pole and slot combination on the vibrations and noise in PMSM. The paper studied two PMSM that have the same performances but different pole and slot combinations using FEA. The authors used 12 slot 9 poles and 9 slots 8 pole combination. The result of the harmonic analysis of the radial force, it was found that the number of slot which is the integral multiple of the harmonic components of the rotor pole is preferred in order to avoid the low harmonic radial force and reduce vibration [14].

Libert and Soulard in analysis of slot-pole combination of fractional-slots PMSM for embedded applications had studied the torque harmonics characteristic using different slot-pole numbers. The aim of the paper is to give an overview of each machine considering the most common slot-pole combination. The slot is varied from 9 slot to 60 slot while the pole is varied from 2 poles to 10 poles. It shows that topologies with 4 poles, same like 2 poles machine. While the 6 poles topologies, the harmonic distortion is very high and high eddy-current losses can be predicted. For 8 slot and 10 poles topologies, the performance of PMSM motor is mixed but the main harmonic is high [15]. Besides above studies, the incompatible design structure is neccessity to improve the torque ripple. Nothcing technique with concentrated winding approach are applied to various structural on stator tooth and rotor of IPMSM. Then, the model is calculated using numerical software of Finite element analysis. The back emf harmonic, radial force density , cogging torque , spatial and time harmoncs of torque rippe is computed to validate the initial model. The finding of this paper shows the air gap lentgh contribute to lower the EMF THD and torque ripple [16].

Another paper that relates to EMF harmonics had been discussed by Washington et. al, in their paper title Reduction of Cogging Torque and EMF Harmonics in Modulated Pole Machines. The paper is basically purposed on the method for reducing cogging torque and harmonic content of back-electromotive force (EMF) waveforms in modulated pole machines (MPM). In their experimental works, separate modulated machine had been applied to reduce the prominent harmonics present in a three-phase MPM cogging torque. The result shows the application of tooth pitching able to reduce the cogging torque and back-EMF harmonics significantly. The result shows a significant impact by comparing between the two measured prototypes [17].

Other method proposed to reduce the torque ripple, rather than using the appropriate slot-pole number variation method is by changing the symmetrical stator teeth design to asymmetric teeth design. This is suggested by Kim et al [18], by simulate nine models of 12 slot 8 poles including the reference model of IPMSM with different angle of middle teeth stator to middle slot opening. The reason of changing the stator structure from symmetrical to asymmetrically is to change the flux path in order to reduce the torque ripple without affecting the average torque. The modeling is simulated using Finite Element Method. Back EMF, torque ripple and total harmonic distortion is calculated and compared to reference model. The result shows this method able to improve $70 \%$ of THD and produce lowest torque ripple by selecting the appropriate asymmetrical stator structure.

Other than that, there are studied about torque ripple reduction on surface mounted Permanent Magnet Brushless DC (PM BLDC) which is used magnet pole shaping technique. The magnet pole offset is varying to investigate the effect of back- EMF, cogging torque and torque ripple. The motivation of this work is from the torque ripple produce by imprecise of the motor position control. The current commutation of PM BLDC required non trapezoidal back EMF, non-ideal rectangular pulse currents to operate. Thus, the magnet pole shaping is used to adjust the correct angle to reduce the cogging torque without any significant reduction of back-EMF. Through the findings, there is a reduction in torque ripple without significant reduction in back EMF and motor efficiency. Thus, the reduction of total harmonic distortion (THD) and harmonic content in torque develop is considerable [19].

The paper of Harmonic Contents in Induced EMF and Electromagnetic Torque in Mass Produced Sinusoidal Permanent Magnet Brushless Machines written by Gebregergis and Sebastian studied on the harmonic content by varying different slot and poles. In this paper, the detailed finding of the harmonic contents in the induced voltage and torque in permanent magnet synchronous motors had been presented. This work used two fractional slot permanent magnet topologies to investigate and analyze the harmonic 
content that is influenced by motor slot-pole and winding configurations. The approach is using various sources that responsible in producing a harmonics through mathematical models involving the induce voltage and the developed torque equation. The theory is presented by analytical formulas and simulated by using the finite element analysis. The anticipation of this paper is both analytical and Finite Element (FE) based modeling is verified for both topologies. It also finds that the harmonic contents especially the $2^{\text {nd }}$ order (electrical) in induced EMF is responsible for causing $3^{\text {rd }}$ order harmonic torque ripple in the developed torque. Thus, various practical causes such as permanent magnet placement and property variations and winding arrangements need to be consider [20]. C. Ocak And A. Dalcali studied the re relationship between the number of poles, slots and winding arrangements in BLDC motors. The studied focused on four pole BLDC motor with different slot numbers $(6,12$ and 15) and winding arrangements. The finite element analysis is used to compute the total harmonic in voltage for every different slot and pole variations. The finding of this work shows that the lowest THD corresponding to sinusoidal back emf is obtained on 15 slots 4pole design [21].

However, the harmonic studies in most literature above only focus on small motor and not intended for HVLS fan application. For this application, the physical sizing of the motor is bigger than above literature which is $1000 \mathrm{~W}$ motor to drive the fan blades. Vibrations and noise that caused by the torque ripple is crucial. It gives significance issue which leads to inefficiency of the application. Therefore, this paper aim to analyze and investigate the effect of the slot-pole combination on EMF harmonics and torque ripples for BLAC motor. The objective is to eliminate the harmonic content in EMF at early stage design and improved the vibrations that occur by torque ripples. In here, the analysis involved three different models with fractional slot windings arrangement. Finite element analysis (FEA) software known as Flux 2D is used to analyses the EMF characteristic. Then, the EMF harmonic characteristic is calculated using Fast Fourier Transform (FFT).

\section{DESIGN AND MODELING OF BLAC MOTOR}

In this section, the modeling is determined by considering requirement of HVLS applications as shown in Table 1. The design methodology is presented as in Figure 1 below. The process of the design and modeling start with process of determine the HVLS fan specifications. The design specifications are basically based on the three phase motor which is commonly used as traction motor on the ceiling fan system. The design of HVLS fan required high torque to rotate the large fan blades at low rotational speed. The basic structure of BLAC motor is illustrated as in Figure 2. The motor is designed at $1000 \mathrm{~W}$ rated power with maximum allowable current at $13 \mathrm{~A}$ due to the material limitations of the BLAC motor. The speed range is set from 50 until $200 \mathrm{rpm}$ to fulfill the speed variation of high volume low speed fan. All modeling is fixed to $160 \mathrm{~mm}$ outer radius and has similar permanent magnet volume but different slot-pole number.

Table 1. Design Specifications

\begin{tabular}{ccc}
\hline Design consideration & Units & Value \\
\hline Input voltage, $V_{\text {in }}$ & {$[\mathrm{V}]$} & AC source 120-240 \\
Max current, $I$ & {$[\mathrm{~A}]$} & 13 \\
Power, $P$ & {$[\mathrm{~W}]$} & 1000 \\
No. phases & & 3 \\
Torque required, $T_{\text {req }}$ & {$[\mathrm{N} . \mathrm{m}]$} & $48-190$ \\
Rated speed range, $\omega$ & {$[\mathrm{rpm}]$} & $50-200$ \\
\hline
\end{tabular}

Next, the selection of stator slot and rotor pole number. In this work, the motor is designed for three phase formations. Thus, the stator slot (s) and pole (p) number is set to $9 \mathrm{~s} / 8 \mathrm{p}, 12 \mathrm{~s} / 10 \mathrm{p}$ and $18 \mathrm{~s} / 20 \mathrm{p}$. The stator design is square type. Initially, the stator sizing of BLAC is basically based on the conventional design method $[22,23,24]$. The design model is set to $160 \mathrm{~mm}$ outer radius by considering the power and volume density that produced by the motor. The rotor bore diameter and the permanent magnet volume are set to be fixed. The thickness of stator yoke is set to be sufficient in order to limit the flux density which is below than knee point of B-H curve material, which is $1.5 \mathrm{~T}$. Next, the rotor sizing is determined based on permanent magnet sizing. Permanent magnet sizing estimation is fundamentally based on the magnetic flux distribution in the magnetic circuit. This BLAC motor used Neodymium Boron Iron $(\mathrm{NdFeB})$ as the material for the permanent magnet. Through the B-H curve of the PM material, the sizing of permanent magnet can be defined by determining the permanent magnet pole area. Next, the rotor sizing is determined based on the permanent magnet sizing. Finally, the complete design structure is tabulated in Table 2 and Figure 3. below. The ampere turns (NI) for each model $9 \mathrm{~s} / 8 \mathrm{p}, 12 \mathrm{~s} / 10 \mathrm{p}$ and $18 \mathrm{~s} / 20 \mathrm{p}$ is fixed. 


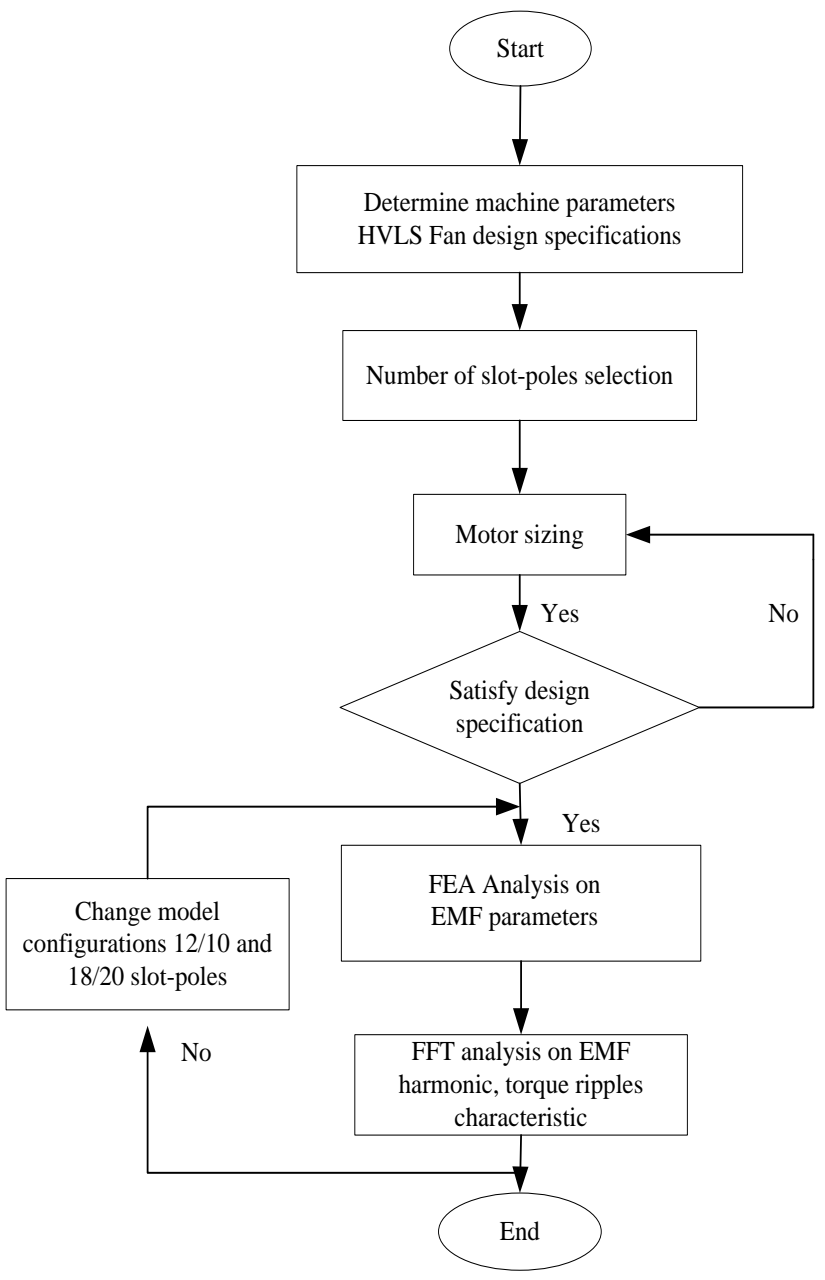

Figure 1. BLAC design methodology

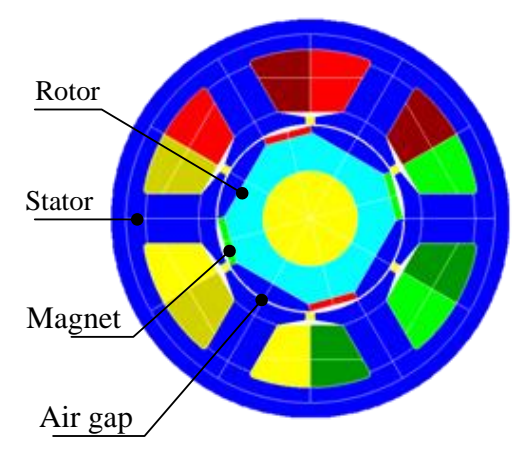

Figure 2. The basic structure of BLAC motor

Table 2. BLAC motor parameter

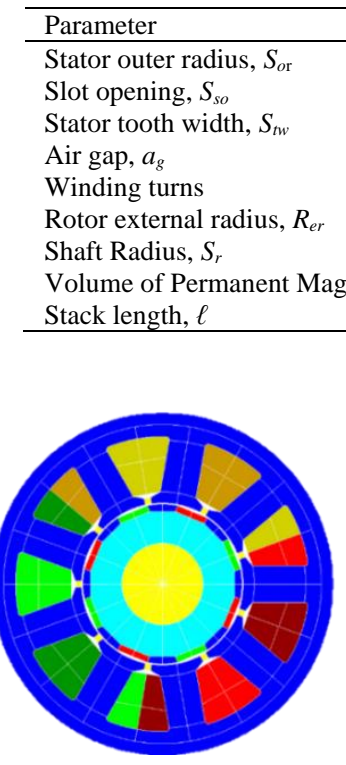

(a)

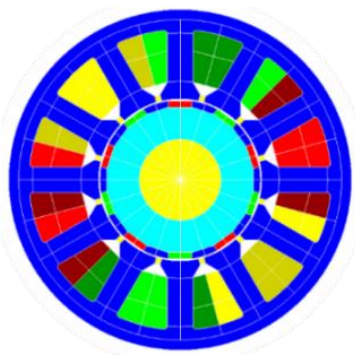

(b)

\begin{tabular}{cccc} 
Units & $9 \mathrm{~s} / 8 \mathrm{p}$ & $12 \mathrm{~s} / 10 \mathrm{p}$ & $18 \mathrm{~s} / 20 \mathrm{p}$ \\
\hline $\mathrm{mm}]$ & & 160 & \\
{$[\mathrm{~mm}]$} & 7 & 5 & 6 \\
{$[\mathrm{~mm}]$} & 19 & 24 & 38 \\
{$[\mathrm{~mm}]$} & & 1 & \\
& 200 & 300 & 307 \\
{$[\mathrm{~mm}]$} & & 74.5 & \\
{$[\mathrm{~mm}]$} & & 38 & \\
{$[\mathrm{~mm}]$} & & $36000 \mathrm{At}$ & \\
{$[\mathrm{mm}]$} & & 105 &
\end{tabular}

Figure 3. BLAC model with the different slot-pole number (a) $9 \mathrm{~s} / 8 \mathrm{p}$ (b) $12 \mathrm{~s} / 10 \mathrm{p}$ (c) $18 \mathrm{~s} / 20 \mathrm{p}$ 


\section{PARAMETER FOR ANALYSIS}

This section will explain on the simulation parameters, in order to determine the harmonic contain in EMF of BLAC motor. The analyses begin with the EMF profile analysis computation, then EMF harmonic analysis and transient torque to determine the torque ripples. All simulation is executed using Flux 2D FEA. Initially, the FEA is used to calculate the electromagnetic field in BLAC motor. The FEA simulation using magnetic vector potential equations which relate to magnetic vector potential (A), magnetic density, (B) and magnetic field intensity, $(\mathrm{H})$. In here, the modelling is simulated using transient magnetic $2 \mathrm{D}$ application and initialized by static computation to analyse the model performance. The simulations involve the EMF computation at no load condition. Later, the analysis of harmonic is executed using Fast Fourier Transform (FFT). Lastly, the transient torque ripple characteristic is presented for three different slot poles.

\subsection{EMF parameters}

Analysis on harmonic EMF characteristic is beginning with EMF computation. The modelling is coupled with external circuit to compute the EMF profile. The simulation executed by using Fujiwara method to analyse the EMF at static condition by compute the relaxation factor using nonlinear system process solver. Figure 4. (a) shows the external circuit connections that coupling with the BLAC model. The simulation is running for one electrical cycle period. This is corresponding to the motor to act as generator mode at no load condition. There is no current supply to the coil winding of every phase and the motor rotates at $200 \mathrm{rpm}$. Coil conductor 1,2 and 3 and $L_{1}, L_{2}$ and $L_{3}$ represent the stator coils, while $R_{1}, R_{2}$ and $R_{3}$ are corresponding armature resistance of the motor. The value of every resistance is designated to be a large value in order to compute the EMF. While the value of inductance $L_{l}$ is set to be constant. Thus, the EMF can be defined by using Equation (1.0) below as referring to the BLAC model simplifies equivalent circuit as in Figure 4.(b). Whereas $V$ is terminal phase voltage, $i$ symbolize of the phase current, $L_{l}$ is Armature self-inductance, $e$ is EMF and $R_{l}$ is phase resistance.

$$
V=i R_{1}+L_{1} \frac{d i}{d t}+e \quad[\mathrm{v}]
$$

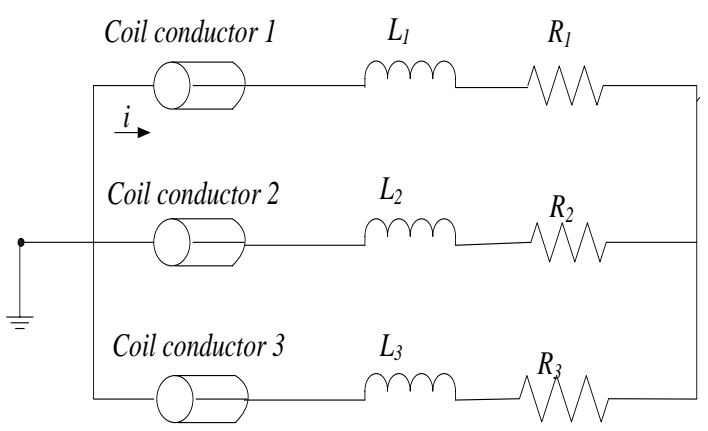

(a)

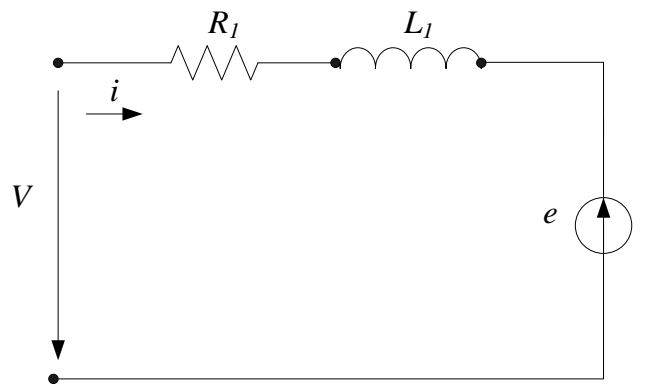

(b)

Figure 4. External circuit connection for BEMF computation (a) External circuit connection (b)The equivalent circuit of BLAC model

Harmonic analysis is the process of calculate the magnitudes and fundamental phases at high order harmonics of the periodic waveform. Usually, the FFT is used to express the periodic function. FFT is a nonperiodic function $f(t)$ in time domain transform to function of $F(\mathrm{~s})$ which is corresponding to frequency domain. For EMF harmonic of BLAC motor, the motor with fractional slot number have a high content harmonic in air gap distribution [25]. The EMF of BLAC motor and torque can be expressed as in Equation (2.0). Whereas $h$ is the harmonic component, $\omega$ is the fundamental frequency in radians per second, and $\theta$ is the phase angle in radians for corresponding harmonic components. Whereas, $e_{a}$ is EMF for phase $a$, the $\lambda_{a}$ is the harmonic coefficient of the BLAC motor flux linkages per pole phase, $\theta_{a}$ is angular position of the rotor. In order to evaluate the correlations EMF harmonics, affect the torque ripples, the total harmonics is calculated using Equation (3.0). Here, the $k$ is an integer which refers to harmonics order $(k=2,3,4)$ and $V_{k} \mathrm{~s}$ the amplitude of $k_{t h}$ order harmonics while $V_{l}$ is the fundamental frequency component.

$$
e_{a}=\sum_{h=1}^{2} h \omega \lambda_{a} \sin \left(h \omega t+\theta_{a}\right) \quad[\mathrm{v}]
$$




\subsection{Transient torque and torque ripples parameters}

Transient torque analysis in BLAC motor is occurs while the motor running at constant speed. Through this simulation, the amounts of torque were produced at a certain speed of rotation with the load. In this analysis, the motor is driven with the three-phase sinusoidal current and rotates at $200 \mathrm{rpm}$. To execute this, the model is coupled to the external circuit as in Figure 5 (a) below as $i_{a}, i_{b}$ and $i_{c}$ represent current sources. The system will feed with the sinusoidal current source based on the Equation in (4.0). Through the Equation (4.0), $I_{\max }$ is maximum allowable current applied to the phase windings, while coil conductor 1, 2, 3 and inductor $L_{a}, L_{b}$, and $L_{c}$ represents the coil windings, meanwhile $R_{a}, R_{b}, R_{c}$ acts as the phase resistance. The $s c_{1}$ and $s c_{2}$ represent as a permanent magnet. The solid conductor is connected with a large series resistance of $R_{4}, R_{5}$ and $R_{6}$. The circuit represents an eddy current in the permanent magnet and the patterns of the permanent magnet are enforced with the zero total current constraints. Thus, the transient torque of BLAC can be calculated using Equation (5.0). In Equation (5.0), $T_{e}$ is transient torque, $e_{a}, e_{b}$ and $e_{c}$ is induced voltage per phase, $i_{a}, i_{b}, i_{c}$ is per phase current and $\omega_{m}$ is mechanical speed.

$$
\begin{aligned}
& i_{a}=i_{\text {max }} \cdot \sin (\omega \mathrm{t}+\alpha) \\
& i_{b}=I_{\text {max }} \cdot \sin \left(\omega \mathrm{t}-\frac{2 \pi}{3}\right) \\
& i_{c}=I_{\text {max }} \cdot \sin \left(\omega \mathrm{t}-\frac{2 \pi}{3}\right)
\end{aligned}
$$

where $I_{\max }$ is maximum current per phase, $\omega_{m}$ is mechanical speed and $\alpha$ is the control angle between phase current corresponding to the phase of EMF. Then,

$$
\begin{array}{lr}
\omega_{m}=2 \pi f & {[\mathrm{rad} / \mathrm{s}]} \\
f=\frac{\text { speed }}{60}\left(\frac{\text { poles }}{2}\right) & {[\mathrm{Hz}]} \\
T_{e}=\frac{e_{a} i_{a}+e_{b} i_{b}+e_{c} i_{c}}{\omega_{m}} & {[\mathrm{Nm}]}
\end{array}
$$

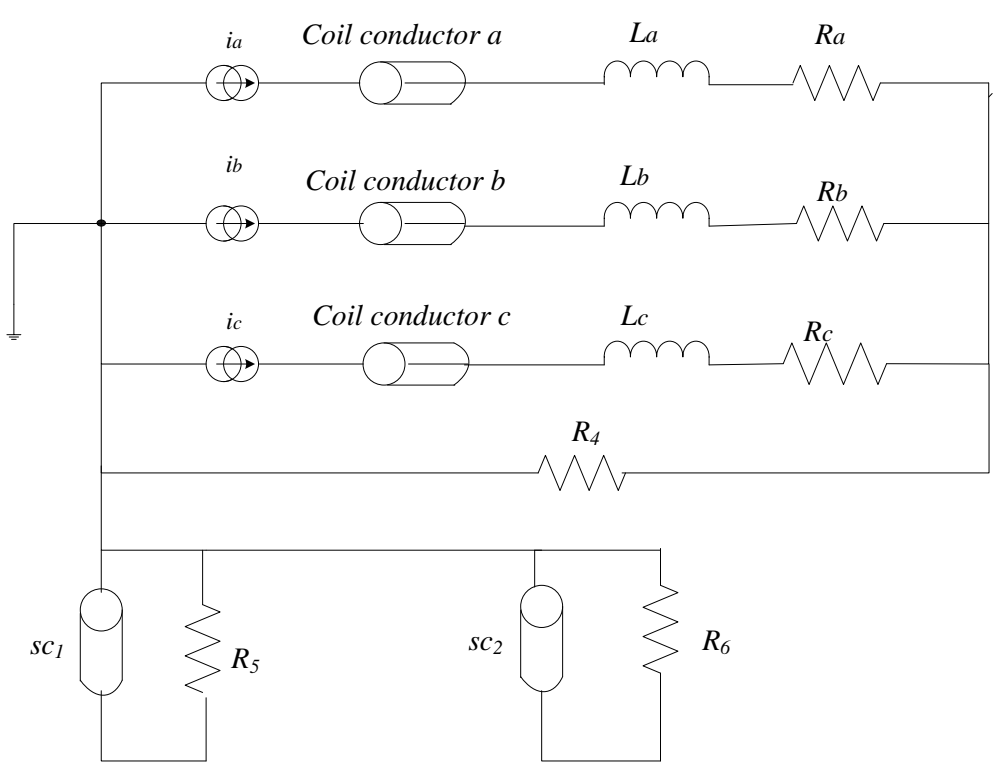

Figure 5. External circuit connection for constant speed analysis

\section{ANALYSIS ON EMF HARMONICS AND TORQUE RIPPLES}

This section explained on the result of EMF profile analysis, EMF harmonic analysis, transient torque and torque ripples. Figure 6 (a) shows the EMF analysis of three different slot-poles number. It shows that the EMF profiles of the three different configurations are nearly the same. The 18 slot 20 poles 
configurations have a higher back-EMF at $133.4 \mathrm{~V}$ compared the other two configurations. Even the permanent magnet volume and NI is same, the EMF value for $9 \mathrm{~s} / 8 \mathrm{p}$ is still the lowest result at $66.29 \mathrm{~V}$.

Figure 6 (b) shows FFT analysis on EMF for each model BLAC motor. The first number of harmonic for three slot-poles is the fundamental of harmonics. The highest harmonics EMF is at $2^{\text {nd }}$ number happened at $18 \mathrm{~s} / 20 \mathrm{p}$ BLAC motor. But during $3^{\text {rd }}$ harmonic number, the harmonic EMF is starting to decrease. The trend line of the harmonic number for three models is same for $18 \mathrm{~s} / 20 \mathrm{p}$ and $12 \mathrm{~s} / 10 \mathrm{p}$. The increasing value of EMF harmonics characteristic happened at second number of harmonics and start reduce while third number of harmonic. While for $9 \mathrm{~s} / 8 \mathrm{p}$ the value of harmonic start to increase after $10^{\text {th }}$ harmonic number.

Figure 6 (c) shows the transient torque analysis. The maximum torque for $18 \mathrm{~s} / 20 \mathrm{p}, 12 \mathrm{~s} / 10 \mathrm{p}$ and $9 \mathrm{~s} / 8 \mathrm{p}$ is $94.2 \mathrm{Nm}, 77.6 \mathrm{Nm}$ and $44.5 \mathrm{Nm}$, respectively. From the result, the torque ripples for $12 \mathrm{~s} / 10 \mathrm{p}$ is higher possibly due to the high cogging torque and control angle of the phase current. Other than that, to reduce the torque ripples the control angle, $\alpha$ is possibly changed to improve the transient torque.

Figure 6 (d) shows the FFT analysis of transient torque for different slot-pole of BLAC motor. Based on the graph, the $9 \mathrm{~s} / 8 \mathrm{p}$ has highest harmonic at $13^{\text {th }}$ number of harmonic. For $12 \mathrm{~s} / 8 \mathrm{p}$ the harmonic is high at $3^{\text {rd }}$ and $9^{\text {th }}$ number of harmonics. The other $18 \mathrm{~s} / 20 \mathrm{p}$ has lowest value of harmonic. Table 3 below shows the torque ripples result of the three models. In order to indicate the low the torque ripple and vibration issue, the EMF harmonics value has to be low. From the table, it shows that, the total harmonic of EMF using FFT analysis for $18 \mathrm{~s} / 20 \mathrm{p}$ is $0.286 \%$ small compared the other two models. As the result, the $18 \mathrm{~s} / 20 \mathrm{p}$ has lower torque ripples compared the other two models. Thus, it can be concluded that the EMF harmonics can be indicator to determine the low torque ripple in model and eliminate vibrations issue.

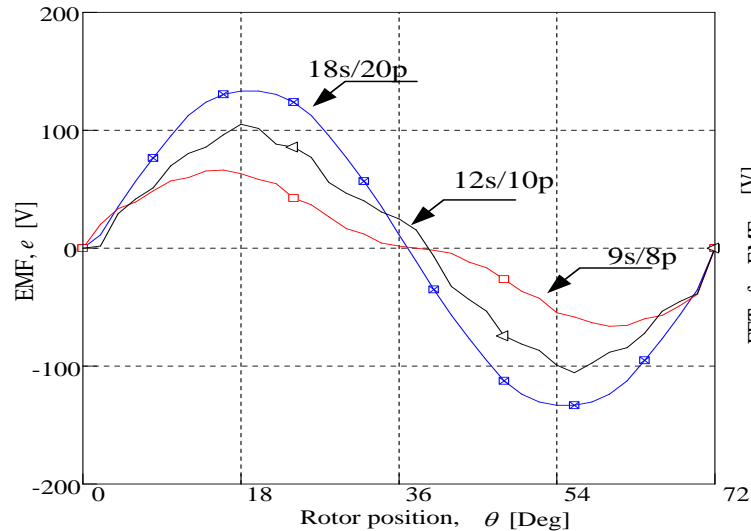

(a)

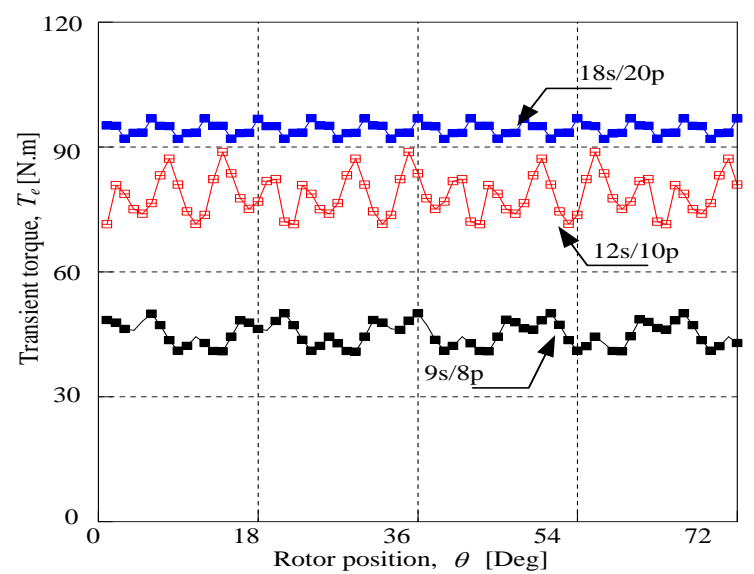

(c)

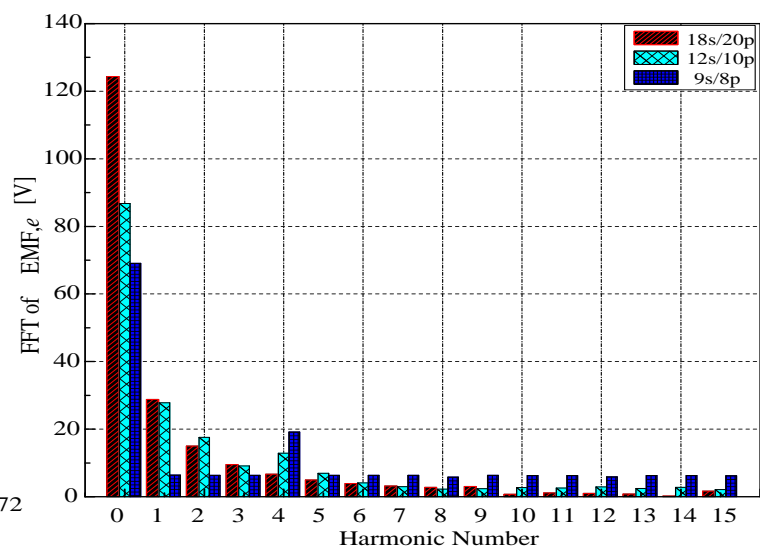

(b)

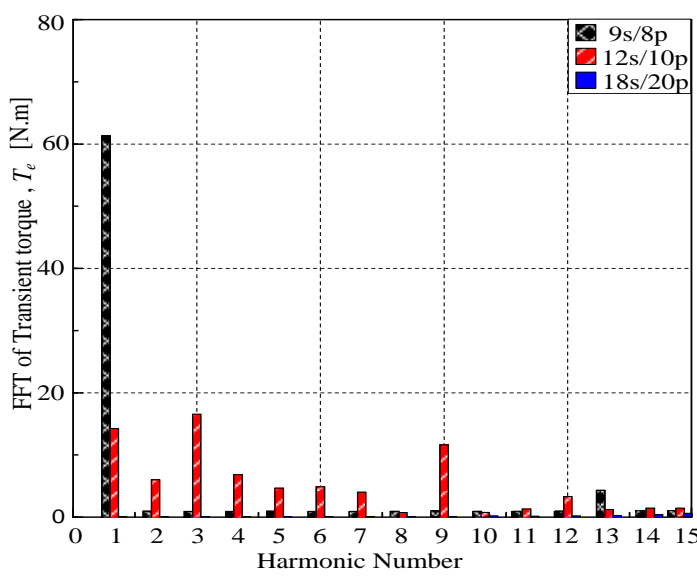

(d)

Figure 6. Torque ripple analysis

(a) EMF characteristic(b) EMF FFT analysis(c)transient torque (d) transient torque FFT analysis

Table 3. Torque ripples result 


\begin{tabular}{lcccc}
\hline \multicolumn{1}{c}{ Model } & Units & $9 \mathrm{~s} / 8 \mathrm{p}$ & $12 \mathrm{~s} / 10 \mathrm{p}$ & $18 \mathrm{~s} / 20 \mathrm{p}$ \\
\hline FFT of Transient Torque & {$[\mathrm{N} . \mathrm{m}]$} & 6.2 & 14.4 & 0.2 \\
Maximum Torque, $T_{\max }$ & {$[\mathrm{N} . \mathrm{m}]$} & 50.05 & 88.77 & 96.87 \\
Minimum Torque, $T_{\min }$ & {$[\mathrm{N} . \mathrm{m}]$} & 40.84 & 39.13 & 91.89 \\
Total harmonics EMF & {$[\mathrm{x} \%]$} & 0.48 & 0.443 & 0.286 \\
Torque ripples & {$[\mathrm{x} \%]$} & 0.18 & 0.56 & 0.051 \\
\hline
\end{tabular}

\section{CONCLUSION}

The three models with design parameters of outer diameter, rotor bore diameter and permanent magnet volume had successfully simulated for EMF computation using FEA analysis. The model is analyzed to evaluate the harmonic on EMF. It shows that $18 \mathrm{~s} / 20 \mathrm{p}$ has 0.05 lowest torque ripples. The EMF contain higher harmonic for $12 \mathrm{~s} / 10 \mathrm{p}$ model at $3^{\text {rd }}$ harmonic number. In conclusion, the EMF harmonic characteristic among different slot-pole number variations affects the torque ripples characteristic for BLAC motor. For further work, the result will be used to study the losses and thermal analysis for similar application. As a conclusion, this research shows effect slot-pole number towards EMF harmonic for HVLS fan application.

\section{ACKNOWLEDGMENT}

The authors would like to thank Ministry of Education Malaysia, Universiti Teknikal Malaysia Melaka (UTeM) for providing the research grants Gluar/SURIAGRANT/2017/FKECERIA/I00020, PJP/2017/FKE/HI12/S01537, GLUAR/PPRN/2017/FKE-CERIA/G0005 and Jurnal/2019/FKE/Q00016. Another special wish is to acknowledge the contribution from Altair Engineering Sdn. Bhd for providing the Flux 2D software package to simulate the model.

\section{REFERENCES}

[1] K. Xia, J. Lu, B. Dong, and C. Bi, "Analysis of acoustic noise from electromagnetic torque ripple for brushless DC motor," in 2016 Asia-Pacific Magnetic Recording Conference, APMRC 2016, 2016, vol. 6, pp. 7-8.

[2] Zulkarnain, N. F., Ibrahim, T. and Romlie, M. F. 'Design and optimization of permanent magnet machine for ceiling fan', International Conference on Intelligent and Advanced Systems, ICIAS 2016, pp. 2-7.

[3] N. Abdullah, R. N. Firdaus, S. Farina, M. Z. Aishah, F. Azhar, and K. A. Karim, "Design of double stator slotted rotor for large ceiling fan application," in IET Conference Publications, 2018, vol. 2018, pp. 7,

[4] Liu, C. 'Development of brushless DC motor with low cogging torque for ceiling fan, 2009 International Conference on Power Electronics and Drive Systems (PEDS), 2009, pp. 778-782.

[5] Kim, K.S., Lee, C.M., Hwang, G.Y., and Hwang, S.M., Effect of the Number of Poles on the Acoustic Noise from BLDC Motors. Journal of Mechanical Science and Technology, 2011, 25(2), pp. 273-277.

[6] K. Xia, Z. Li, J. Lu, B. Dong, and C. Bi, “Acoustic noise of brushless DC motors induced by electromagnetic torque ripple," J. Power Electron., 2017, vol. 17, no. 4, pp. 963-971.

[7] Saxena, A. and Fernandes, B. G. 'Noise and cogging torque reduction in brushless DC ceiling fan', in 2015 18th International Conference on Electrical Machines and Systems, ICEMS 2015. pp. 1334-1338.

[8] N. Shah, N. Sathaye, A. Phadke, and V. Letschert, "Efficiency improvement opportunities for ceiling fans," Energy Effic., 2014, vol. 8, no. 1, pp. 37-50.

[9] Bobba, D., Li, Y., and Sarlioglu, B., 2015. Harmonic Analysis of Low Stator Slot and Rotor Pole Combination FSPM Machine Topology for High Speed. IEEE Transaction on Magnetics, 1-4(July).

[10] Mohammed, O.A., Ieee, F., Liu, S., Ieee, M., Abed, N., and Member, S. Effect of Increasing Pole Number on the Harmonic Content of Air-Gap Flux Density Waveforms in Electric Machines. IEEE Southeast Con, 2004. Proceedings.pp. 4-6.

[11] Zhu, Z.Q., and Howe, D. Influence of Design Parameters on Cogging Torque in Permanent Magnet Machines. IEEE Transactions on Energy Conversion, 2000. 15(4), pp. 407-412.

[12] J. Hur and B. W. Kim, "Rotor shape design of an interior PM type BLDC motor for improving mechanical vibration and EMI characteristics," Journal of Electrical Engineering and Technology, 2010. Vol. 5, no. 3, pp. 462-467.

[13] T. Srisiriwanna and M. Konghirun, "A study of cogging torque reduction methods in brushless DC motor," in 2012 9th International Conference on Electrical Engineering/Electronics, Computer, Telecommunications and Information Technology, ECTI-CON 2012, 2012, pp. 1-4

[14] Sun, T., and Hong, J.P. Effect of Pole and Slot Combination on Noise and Vibration in Permanent Magnet Synchronous Motor. IEEE Transaction on Magnetics, 2011. 47, pp. 1038-1041.

[15] Libert, F., and Soulard, J. Investigation on Pole-Slot Combinations for Permanent-Magnet Machines with Concentrated Windings. International Conference on Electrical Machines (ICEM), 2004. pp. 5-8.

[16] Jeon, K. et al. 'Numerical Shape Design Characteristics of Torque Ripple Reduction for Interior Permanent Magnet Synchronous Motor', 9th IET International Conference on Computation in Electromagnetics (CEM 2014), pp. 2-3. 
[17] Washington, J.G., Atkinson, G.J., Baker, N.J., Reduction of Cogging Torque and EMF Harmonics in Modulated Pole Machines. IEEE Transactions on Energy Conversion. 2016. 31, 759-768.

[18] H. M. Kim, Y. J. Kim, and S. Y. Jung, "Torque ripple and back EMF harmonic reduction of IPMSM with asymmetrical stator design,” 2017, doi: 10.1109/ICEMS.2017.8056477.

[19] Upadhayay, P. and Rajagopal, K. R. 'Torque ripple reduction using magnet pole shaping in a surface mounted Permanent Magnet BLDC motor', in Proceedings of 2013 International Conference on Renewable Energy Research and Applications, ICRERA 2013, pp. 516-521.

[20] Gebregergis, A., and Sebastian, T., 2012. Harmonic Contents in Induced EMF and Electromagnetic Torque in Mass Produced Sinusoidal PM Brushless Machines. IEEE Energy Conversion Congress and Exposition (ECCE). 2012. pp. 3040-3047.

[21] C. Ocak and A. Dalcali, "A comparative analysis of four-pole brushless DC motors with different slot and winding arrangement based on THD values," Int. J. Energy Appl. Technol., vol. 7, no. 1, pp. 7-12, 2020.

[22] Hendershot, J.R., and Miller, T.J.E., 2010. Design of Brushless Permanent-Magnet Machines, Motor Design Books. Magna Physic Publishing \& Oxford University Press, 2010, 88-89.

[23] R. Nor, F. Raja, F. Sulaiman, S. Rizuan, and K. A. Karim, "Design of Hollow-Rotor Brushless DC Motor," Int. J. Power Electron. Drive Syst., vol. 7, no. 2, pp. 387-397, 2016.

[24] S. Farina, R. N. Firdaus, M. S. Ahmad, A. Jidin, and T. Sutikno, "Winding Arrangement of a New Type Hollow Rotor BLDC Motor," Int. J. Power Electron. Drive Syst., vol. 9, no. 3, pp. 933-946, 2018.

[25] Chen, A., Nilssen, R., and Nysveen, A., 2008. Harmonic Analysis and Comparison of the Back EMFs of Four Permanent Magnet Machine with Different Winding Arrangements. Proceedings of the 11th International Conference on Electrical Machines and Systems, ICEMS 2008, pp. 3043-3048.

\section{BIOGRAPHIES OF AUTHORS}
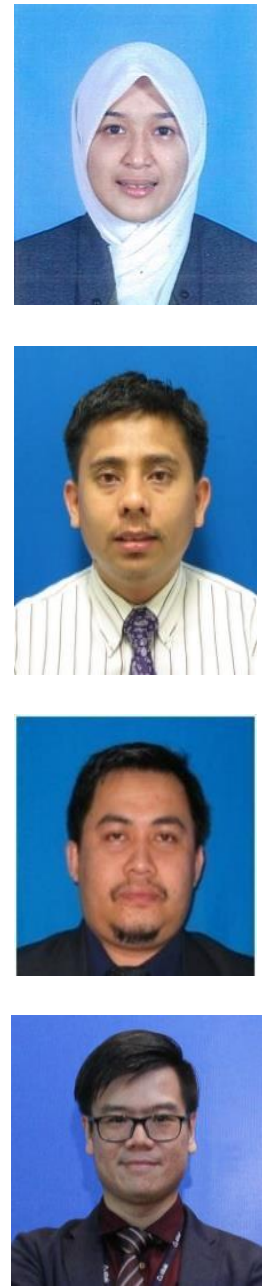

Nurfaezah Abdullah was born in Kuala Lumpur. She had received B.Eng. in Power Electronics and Drives in 2012 and M.Sc. Electrical Engineering at Universiti Teknikal Malaysia Melaka. Currently, she is pursuing her PhD at Universiti Teknikal Malaysia Melaka. Her research interest includes the field in machine design, photovoltaic system and power electronics.
Raja Nor Firdaus Raja Othman was born on 02 May 1982 at Parit Buntar, Perak, Malaysia. He received B.Eng., M.Sc. and Ph.D in Electrical Power Engineering from Universiti Putra Malaysia in 2006, 2009 and 2013, respectively. He is currently associate professor at Faculty of Electrical Engineering, Universiti Teknikal Malaysia Melaka. His research interest includes applied magnetics, electrical machines, magnetic sensor and drives.

Kasrul Abdul Karim received the M.Sc. from University of Bradford and Ph.D. degrees from the University of Nottingham, UK, in 2003 and 2011, respectively. He is currently associate professor at Faculty of Electrical Engineering, Universiti Teknikal Malaysia Melaka, Durian Tunggal, Malaysia. His research interests include electrical machine design, power electronics, and electric vehicle.

Lim Seng Tat started the career as CAE engineer for automotive industry. He is now working as a sales director of Altair Engineering in charge of Malaysia \& Philippines.Hehad conducted more than 100 of workshops, trainings \& technology events across ASEAN region; with covered the topics across different industries including automotive, aerospace, manufacturing, electronics, appliance, defense, etc. Now, he is currently focusing on business development for both Malaysia and Philippines. 